\title{
Medical Toxicology and Public Health: Update on Research and Activities at the Centers for Disease Control and Prevention and the Agency for Toxic Substances and Disease Registry
}

\author{
Introduction to Activities at the Radiation Studies Branch
}

\author{
Ziad N. Kazzi • Jeffrey B. Nemhauser • Armin Ansari • \\ Carol McCurley • Robert Whitcomb • Charles Miller
}

Published online: 1 April 2010

(C) American College of Medical Toxicology 2010

Keywords Radiation - Medical toxicology ·

Centers for Disease Control and Prevention

\section{Background}

The Radiation Studies Branch (RSB) was formed in 1989 as part of the Division of Environmental Hazards and Health Effects in the Centers for Disease Control and Prevention's National Center for Environmental Health (NCEH) [Fig. 1]. At that time, branch staff focused primarily on assessing the potential environmental health effect of radiation released from Department of Energy Nuclear Weapons Production Facilities. After the events of September 11, 2001, however, the RSB assumed additional responsibilities in public health preparedness. This effort is

The findings and conclusions in this article are those of the authors and do not necessarily represent the views of the Centers for Disease Control and Prevention or the Agency for Toxic Substances and Disease Registry.

The following is an update on research and activities in which clinical toxicologists are actively involved at CDC/ATSDR. The Journal of Medical Toxicology will periodically highlight some of these activities to illustrate the growing relationship between clinical toxicology and public health.

Z. N. Kazzi $(\bowtie) \cdot J$. B. Nemhauser · A. Ansari · C. McCurley • R. Whitcomb $\cdot$ C. Miller

Radiation Studies Branch, Division of Environmental Hazards and Health Effects, National Center for Environmental Health, Centers for Disease Control and Prevention,

4770 Buford Highway, NE (MS-F58),

Atlanta, GA 30341, USA

e-mail: zkazzi@cdc.gov largely directed toward preparing the nation's public health community, healthcare providers, and citizens for various scenarios. These include intentional (i.e., terrorism-related) radiological incidents, accidents involving radiation exposure, and unintentional environmental releases of radioactive materials.

Terrorism-related radiation events will likely vary in their form, magnitude, and the specific challenges they pose. An improvised nuclear device that detonates, ${ }^{1}$ for example, will lead to devastating injuries from trauma, burns, and radiation exposure. Moreover, the healthcare infrastructure surrounding the epicenter of such an event will be destroyed and mass evacuation will be needed [1]. If radiation material is dispersed - either covertly or overtlymany will be significantly affected psychologically and economically. This would be similar to the Goiânia Cesium-137 incident of 1987 in which radioactive material was inadvertently dispersed among a group of people. Many concerned citizens required screening, and large areas required decontamination and cleanup. This surge in the number of potential patients will stress and likely overwhelm existing healthcare resources [2].

As RSB's mission broadened in the aftermath of the events of $9 / 11$, medical toxicologists were sought as natural team members in the preparedness and response to radiation emergencies. Medical toxicologists are physicians

\footnotetext{
${ }^{1}$ An improvised nuclear device is a nuclear weapon that has been stolen or illicitly bought from a nuclear state. Alternatively, it may have been assembled by use of stolen weapons' material or from scratch. When it detonates, it will lead to injuries similar to those caused by a nuclear weapon detonation.
} 
Fig. 1 Organization chart of the National Center for Environmental Health/Agency for Toxic Substances and Disease Registry (Simplified)

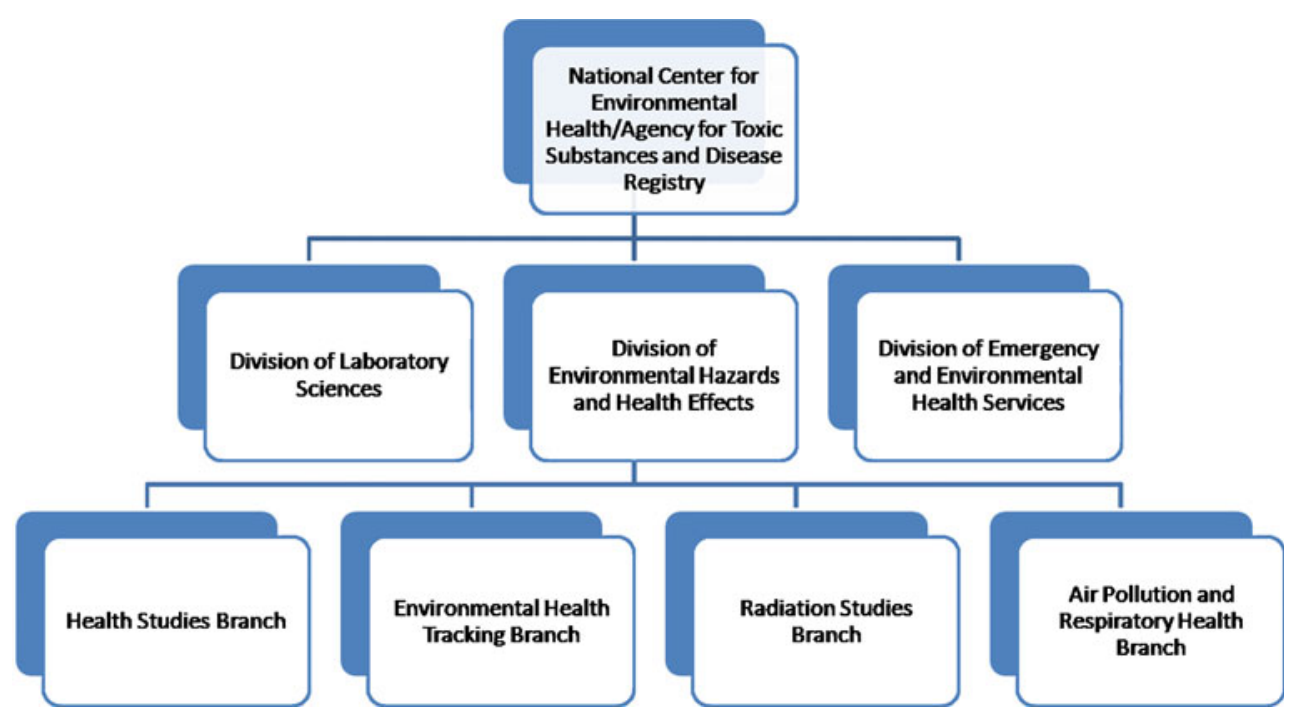

who specialize in managing victims who are injured by agents that are themselves also hazardous to emergency responders. Such toxicologists regularly practice or offer guidance to healthcare workers in the areas of triage, decontamination, and treatment of those exposed to or contaminated by poisons. Their need in the field of radiological public health preparedness and response is due to an insufficient number of medical experts in radiation injury care.

RSB scientists meet these challenges and address the effect of radiation events through collaboration with several academic and nonacademic partners [3]. RSB staff are involved in several different activities, including creating effective educational, training, and communication materials to help response professionals and the general public with emergency preparedness; supporting research related to emergency response and radiation exposure, developing materials that provide guidance for state, local, and tribal public health agencies; and partnering with state, local, tribal and federal public health agencies, as well as with national professional organizations.

\section{Current Activities}

\section{Education/Training/Communication}

Since 2004, NCEH and the Agency for Toxic Substances and Disease Registry have organized ten radiation emergency training courses as a result of a successful cooperative agreement with the American College of Medical Toxicology. More than 300 clinical toxicologists and specialists in poison information systems have participated in these courses held at the Radiation Emergency Assistance Center/Training Site in Oak Ridge, TN, USA. This training covers the handling of radiation emergencies and emphasizes the relevance of medical toxicology to the CDC mission.

During the 2009 session of the North American Congress of Clinical Toxicology, CDC medical toxicologists and epidemiologists introduced RSB resources to attendees and helped organize the American Academy of Clinical Toxicology (AACT) Radiation Special Interest Group Symposium. This symposium, entitled "Internal Contamination with Radionuclides: Diagnosis and Management," attracted more than 60 people, underscoring the interest in this topic. Currently, the AACT Radiation Special Interest Group has more than 40 members from the clinical toxicology community [4]. Information about how to join can be found at http://clintox.org/radsig.cfm.

The RSB Radiation Assessment (RA) Team provides technical and subject matter expertise. The RA Team is comprised of medical toxicologists, health physicists, and other scientists. The team's job is to ensure that branch research, information, and materials are technically accurate. RA Team members serve such additional roles as offering guidance to healthcare workers about the proper use of medical countermeasures in radiation events and staffing the CDC Emergency Operation Center in the event of a nuclear or radiological emergency. During two recent exercises involving terrorist releases of radiological material-TOPOFF 4 and Empire 09-RSB members served both as planners and as active participants, partnering with other federal, state, and local radiation experts and public health officials. Similarly, RSB medical toxicologists serve on the editorial board of the U.S. Department of Health and Human Services Radiation Event Medical Management Web portal [5].

Because accurate and targeted risk communication is essential in the event of a radiological incident, RSB has developed a Communication Team. This team is continuously developing and refining communication strategies, 
and it frequently relies upon medical toxicology support for designing related medical content. Such content can be found in the RSB fact sheets and in other online and paperbased resources [3].

Research Activities in Radiation Exposure and Emergency Preparedness

During the past several years, RSB researchers have examined the potential health effects of environmental contamination from different types of nuclear sites, such as those in Los Alamos (New Mexico), Hanford (Washington State), Fernald (Ohio), and Savannah River (South Carolina). Partners from both the federal and private sectors collaborated with RSB to conduct research at these sites and to draft final reports [3]. As an example, RSB scientists reviewed and calculated the chemical and radioactive releases produced by the Savannah River nuclear site since the 1950s. This site produced plutonium and tritium used to manufacture nuclear weapons [6].

RSB medical toxicologists have authored several papers in the field of radiological public health preparedness and protocols such as an Investigational New Drug Application for using colony stimulating factors for treating acute radiation syndrome. In the field of radiation detection, RSB staff members have collaborated with academic and industry partners to evaluate various hand-held and hospital-based detection equipment adapted to rapidly triage and screen patients. After a radiation mass casualty event, these instruments could be used to evaluate patients who were internally contaminated with radiological material.

RSB scientists and medical toxicologists also evaluate activated charcoal as a potential medical countermeasure for treating internal contamination, and they assess iatrogenic ionizing radiation exposure from medical procedures.

\section{Guidance Materials}

CDC collaborates with other federal agencies, such as the Environmental Protection Agency, and it has published "A Citizen's Guide to Radon," which has been widely used to inform people about the risks of radon exposure in their residences [7].

In 2006, some U.S. citizens traveling abroad in Great Britain were at risk of contamination with radioactive polonium-210, having been in London during the time period surrounding the death of Mr. Alexander Litvinenko. RSB "subject matter experts" informed those at risk (and their physicians) about evaluation and screening options. Additionally, RSB health physicists and medical toxicologists authored and published fact sheets about polonium210. Health physicists designed a dose-reconstruction model for interpreting the results of urinary assays for polonium-210.

Recently, RSB staff have authored a guidance document on population monitoring after a radiological emergency. This guide will assist local and state public health officials in evaluating their emergency preparedness plans and in identifying their needs during such incidents [8].

\section{Partnerships}

RSB staff members are committed to fostering solid partnerships with state, local, tribal, and federal public health agencies, as well as with national professional organizations. As an example, RSB has developed guidance for screening people at Community Reception Centers following a radiological emergency. These centers will be staffed with health physicists, nurses, and physicians, and they are envisioned as locations where citizens who may have been contaminated with or exposed to radiation can be screened, assisted with decontamination (as needed), registered, and prioritized for further follow-up or immediate care. These centers will require collaborative efforts among multiple local and state agencies.

In 2010, RSB staff will collaborate with the National Association of City and County Health Officials to host a roundtable addressing how to conduct and support operations at public shelters during a nuclear emergency. Representatives from various stakeholders, such as the Federal Emergency Management Agency, the American Red Cross, state radiation control programs, and county health departments will participate in this roundtable. Similarly, RSB staff members collaborate with other federal agencies, such as the Biomedical Advanced Research and Development Authority, to determine needs and direct further research efforts in the field of radiation emergencies.

\section{Summary}

Although the RSB was originally formed to evaluate environmental releases from nuclear weapons production facilities, it has broadened its scope to public health issues involving radiation. Currently, its mission centers on enhancing public health through research, education, communication, preparedness, and response. Medical toxicologists at the RSB play an integral role in many of these functions.

\section{References}

1. Dallas CE, Bell WC (2007) Prediction modeling to determine the adequacy of medical response to urban nuclear attack. Disaster Med Public Health Prep 1(2):80-89 
2. International Atomic Energy Agency [Webpage on the Internet]. Vienna, Austria: International Atomic Energy Agency publications: "The Radiological Accident in Goiânia". [cited 2009 Nov 04]. Available from: http://www-pub.iaea.org/.

3. Radiation Studies Branch [Webpage on the Internet]. Radiation studies. Atlanta, GA: Radiation Studies Branch [updated 2007 Oct 10; cited 2008 Nov 04]. Available from: http:/www.cdc.gov/nceh/radiation/.

4. The American Academy of Clinical Toxicology. [Webpage on the Internet]. Radiation Special Interest Group. Wynnewood, PA: The American Academy of Clinical Toxicology [cited 2009 Nov 05]. Available from: http://www.clintox.org/radsig.cfm.

5. U.S. Department of Health and Human Services. [Webpage on the Internet]. Radiation event medical management. Washington, DC: U.S. Department of Health and Human Services [updated 2010 Jan 10; cited 2009 Jan 04]. Available from: www.remm.nlm.gov.
6. Radiation Studies Branch [Webpage on the Internet]. Project profiles-Savannah River Site (SRS). Atlanta, GA: Radiation Studies Branch [updated 2007 Oct 10; cited 2009 Dec 12]. Available from: http://www.cdc.gov/nceh/radiation/brochure/profile savannah.htm.

7. U.S. Environmental Protection Agency [Webpage on the Internet]. A citizen's guide to radon. Washington, DC: U.S. Environmental Protection Agency [updated 2010 Jan 29; cited 2009 Dec 29]. Available from: http://www.epa.gov/radon/pubs/citguide.html.

8. Centers for Disease Control and Prevention, Radiation Studies Branch [Webpage on the Internet]. Population monitoring in radiation emergencies: a guide for state and local public health planners. Atlanta, GA: Centers for Disease Control and Prevention [updated 2007 Aug; cited 2009 Dec 29]. Available from: http:// emergency.cdc.gov/radiation/pdf/population-monitoring-guide.pdf. 